\title{
Infarct Pattern in Patients with Varying Degrees of Internal Carotid Artery Stenosis
}

\author{
MUZAHID MAA ${ }^{1 *}$, SHAIKH MAK ${ }^{2}$, SHAHIDULLAH M ${ }^{3}$, CHOWDHURY A $^{4}$, SAHA ${ }^{5}$, ROY ${ }^{6}$, \\ KABIR MS ${ }^{7}$, DEY SK ${ }^{8}$, AHMED A $^{9}$, ISLAM MR ${ }^{10}$.
}

\begin{abstract}
:
Background: Internal carotid artery (ICA) is one of the commonest site stenosis in patients with ischemic stroke. There is difference in the distribution of stenosis among different sites of cerebral infarct. Volume and severity of cerebral infarct may also depend on the degree of stenosis. To plan efficient evaluation and treatment of individual patient of ischemic stroke, the responsible clinician must be familiar with the relative probability of finding occlusive lesions at various sites within the vascular tree. Objective: The objective of this study was to evaluate the angiographic pattern of ICA stenosis among different types of cerebral infarct. Materials and Methods: We evaluated 53 ischemic stroke patients from indoor, outdoor, stroke and neuro intervention clinic, BSMMU. CT scan and/ or MRI of brain were done to each patient to confirm the diagnosis. After vascular imaging, the degree of stenosis was measured by the NASCET formula. Results: Cervical segment of ICA was most commonly [ $n=45(84.9 \%)]$ encountered site of stenosis and total occlusion of ICA was always observed in cervical segment. Among patients with moderate stenosis $(n=15)$ of ICA, 6(40.0\%) presented with subcortical infarction, 4(26.7\%) presented with lacunar infarction and 5(33.0\%) presented with territorial infarction. In case of severe stenosis $(n=23)$, territorial, lacunar and watershed infarct were 9(39.1\%), 8(34.8\%) and $2(8.7 \%)$ respectively. Whereas total occlusion $(n=15)$ of ICA presented as either territorial infarction $[n=11(73.3 \%)]$ or watershed infarction $[n=4(26.7 \%)]$. These differences between severity of stenosis and subtype of infarct were also significant ( $p$-value $=0.003)$. $A$ total of 25 patients presented with territorial infarction, mostly MCA territory [ $n=23(92 \%)]$. Conclusion: With increasing severity of stenosis, the infarct burden rises. ICA stenosis of e"70\% mainly presented as territorial infarction whereas, watershed infarct was an indicator of severe stenosis.
\end{abstract}

Key Words: Ischemic Stroke, ICA Stenosis, Angiography, Infarct Pattern.

\section{Introduction:}

There are over 13.7 million new strokes each year and one in every four people worldwide over the age of 25 will experience a stroke in their lifetime ${ }^{1}$. Worldwide, $70 \%$ of strokes and $87 \%$ of both strokerelated deaths and disability-adjusted life years occur in the developing areas. On average, stroke occurs 15 years earlier in these areas affecting individuals at the peak of their productive life ${ }^{2}$. According to the latest WHO data from 2020, stroke deaths in Bangladesh reached 118,918 or $15.31 \%$ of total deaths. The age adjusted death rate is 110.89 per 100,000 of population, which ranks Bangladesh 41 in the world ${ }^{3}$.

Atherosclerosis affecting extracranial and intracranial blood vessels is an important and well recognized cause of cerebral ischemia. Carotid atherosclerosis is recognized as the most common vascular lesion in stroke patients ${ }^{4}$. Stroke risk is ten times higher in patients with more than $80 \%$

1. Md. Abdullah Al Muzahid, Phase B Resident, Department of Neurology, BSMMU.

2. Md. Abdul Kader Shaikh, Associate Professor, Department of Neurology, BSMMU.

3. MD. Shahidullah, Associate Professor, Department of Neurology, BSMMU.

4. Ashish Chowdhury, Phase B Resident, Department of Neurology, BSMMU.

5. Sujan Saha, Phase B Resident, Department of Neurology, BSMMU.

6. Uttam Roy, Phase B Resident, Department of Neurology, BSMMU.

7. Md. Suman Kabir, Phase B Resident, Department of Neurology, BSMMU.

8. Subash Kanti Dey, Associate Professor, Department of Neurology, BSMMU.

9. Anis Ahmed, Assistant Professor, Department of Neurology, BSMMU.

10. Md. Rafiqul Islam, Professor and Chairman, Department of Neurology, BSMMU. 
stenosis of carotid arteries than patients with less than $40 \%$ carotid stenosis ${ }^{5}$. Atherosclerosis of major cerebral arteries leads to changes ranging from minor wall thickening to near total occlusion, and may occur in isolation or with systemic atherosclerosis ${ }^{6}$. In situ thrombotic occlusion, artery-to-artery embolism, hypoperfusion, branch atheromatous disease or the combination of these mechanisms lead to cerebral ischemia in patients with atherosclerotic stenosis ${ }^{7}$.

Embolism from proximal artery may cause acute obstruction of distal cerebral arteries producing territorial infarction or lacunar infarction, whereas hemodynamically significant stenosis or obstruction of intracranial arteries may cause ischemia in the distal regions of hemisphere causing the so-called border zone infarction ${ }^{8}$. Collateral flow through circle of Willis and collaterals from pial arterioles connecting two major cerebral arteries affect significantly the outcome of acute arterial obstruction by providing alternate routes for blood flow in the setting of acute ischemic stroke ${ }^{4}$.

\section{Methods}

\section{Patient selection}

This cross-sectional observational study was carried out with an aim to find out the infarct pattern of ICA stenosis among different subtypes of ischemic stroke patients purposively selected from Inpatient, Outpatient and Stroke \& NeuroIntervention clinic of BSMMU. Only the patients with first ever ischemic stroke having significant symptomatic stenosis ( $\geq 50 \%$ stenosis) on angiography, presenting within 14 days of symptom onset were included in this study. Patients with previous stroke, concomitant arterial embolism of limbs or other parts of body, or presumed cardioembolic sources (rheumatic heart disease, atrial fibrillation, prosthetic heart valves, recent myocardial infarction, cardiomyopathy) were excluded.

\section{Clinical evaluation}

Total 155 patients with ischemic stroke were preliminarily selected, among them 12 had previous stroke, 17 had cardioembolic factors present and were excluded. 25 patients had normal angiographic findings and 40 patients having stenosis in vessel other than ICA were excluded from the study. 8 patients had insufficient data and were excluded. So total 53 patients with ischemic stroke who had significant stenosis of ICA were selected as cases. After ethical clearance from Institutional Review Board (IRB), informed written consent was taken from each patient or his/her attendant. Proper history was taken, physical and neurological examination, keeping in mind of the demographic and clinical variables, were done. All relevant investigations were completed including CT Scan of brain or MRI of brain with DWI sequence.

\section{Angiographic Evaluation}

Cerebral angiogram was performed within 30 days of presentation. Angiography was performed by any of the modalities like MRA, CTA or DSA, the one being more feasible for the patient, as advised by the attending consultant. In total 48 of our patients underwent DSA and 33 patients underwent TOF MRA. In angiogram, the degree of stenosis was measured according to the North American Symptomatic Carotid Endarterectomy Trial (NASCET) ${ }^{9}$.

Percentage of Stenosis $=[(D n-D s) / D n] \times 100$, where $D \mathrm{n}$ is normal diameter and

$D$ s is stenosed diameter.

Then, we classified the patients into 3 groups according to the following grading scale: moderate (50\%-69\%), severe (70-99\%), or total occlusion (no flow detected) ${ }^{10}$. A stenotic lesion which was at or above the petrous part of ICA was considered as intracranial stenosis whereas, stenotic lesion proximal to the petrous part of ICA was considered as extracranial stenosis ${ }^{11}$.

\section{Topography of infarct}

Topography of infarct was determined by commonly accepted arterial territories and watershed areas ${ }^{12}$. Each infarct was subdivided into one of four subtypes: territorial, subcortical, lacunar or watershed zone infarct.Territorial infarction was considered when a large ischemic lesion involving the cerebral cortex and subcortical structures in 1 or more major cerebral artery territories was encountered ${ }^{8}$. It was subdivided into ACA, MCA or PCA territory infarct according to accepted cortical supply ${ }^{12}$. Subcortical infarction was considered when (a) the infarcts are restricted to the basal ganglia and/or white matter and the overlying cerebral cortex appears normal; and (b) the maximum diameter of the lesion was more than $20 \mathrm{~mm}^{13}$. Small infarcts, occurring in the white matter, deep grey matter nuclei, and brainstem; 
and of less than $15 \mathrm{~mm}$ in diameter was considered as lacunar infarct ${ }^{14}$. Watershed infarction were lesions in one of the hemodynamic risk zones between major cerebrovascular territories: the superficial border zones wedged between the ACA and MCA or between the MCA and PCA, and the deep border zone located in the vascular territory between deep and superficial arterial systems ${ }^{8}$.

\section{Statistical Analysis}

All the data were rechecked after collection. Continuous variables were expressed as Mean \pm SD. Categorical variables were presented by frequency, percentage and graph. Qualitative data were analyzed by chi-square test. $P$ value of $<0.05$ was considered statistically significant. Statistical
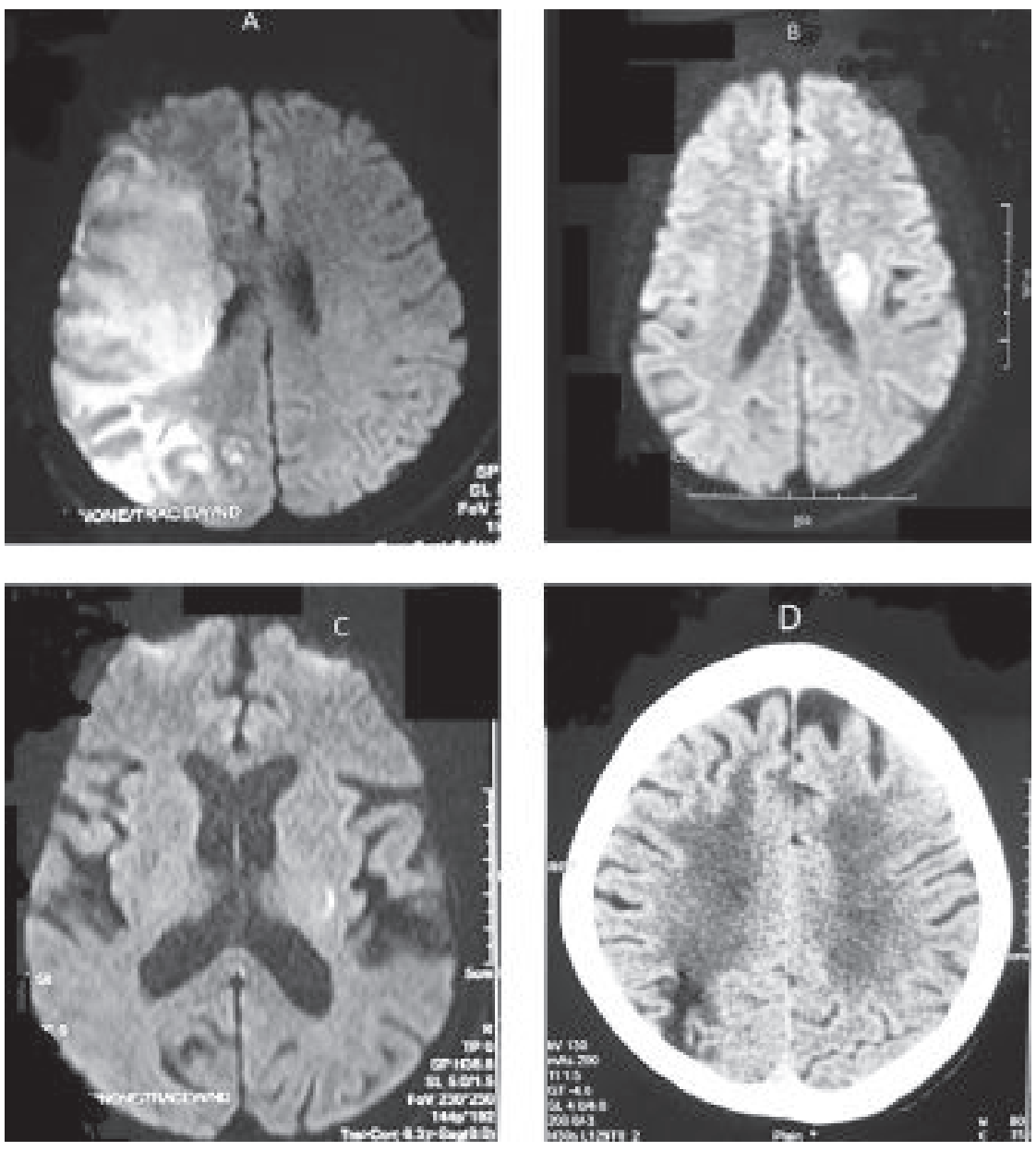

Fig.-I: Definition of infarct pattern. A: MRI-DWI sequence showing territorial infarct involving right MCA territory. B: MRI-DWI sequence showing subcortical infarct involving left side. C: MRI-DWI sequence showing lacunar infarct involving left internal capsule. D: CT scan showing watershed infarct between right MCA and PCA territory. 
patients with stenosis of cervical segment of ICA, $24(53.3 \%)$ had territorial infarct, $8(17.8 \%)$ had lacunar infarct, $7(15.6 \%)$ had subcortical infarct and $6(13.3 \%)$ had watershed infarct. Four patients with stenosis in cavernous part had subcortical $[n=2(50.0 \%)]$ and lacunar $[n=2(50.0 \%)]$ infarct. Four patients with stenosis in supraclinoid part had lacunar $[n=3(75.0 \%)]$ and territorial $[n=1(25.5 \%)]$ infarct. This observation was statistically significant $(p-$ value $=0.041)($ Table II $)$.

Among 15 patients with moderate stenosis of ICA, $6(40.0 \%)$ presented with subcortical infarction,
$4(26.7 \%)$ presented with lacunar infarction and $5(33.0 \%)$ presented with territorial infarction. In case of severe stenosis, territorial, lacunar and watershed infarct were 9(39.1\%), 8(34.8\%) and $2(8.7 \%)$ respectively. Whereas total occlusion of ICA presented as either territorial infarction $[n=11(73.3 \%)]$ or watershed infarction $[n=$ $4(26.7 \%)]$. These differences between severity of stenosis and subtype of infarct were also significant $(p$-value $=0.003)($ Table III).A total of 25 patients presented with territorial infarction, mostly MCA territory[n=23(92\%)]. ACA and PCA territory were observed in $1(4.0 \%)$ each (Table IV).

Table-I

Distribution of age of the study population according to sex type $(n=53)$

\begin{tabular}{|c|c|c|c|c|}
\hline \multirow[t]{2}{*}{ Age of Patient } & \multicolumn{2}{|c|}{ Sex type of Patient } & \multirow[t]{2}{*}{ Total } & \multirow[t]{2}{*}{ P-value } \\
\hline & Male & Female & & \\
\hline$<40$ years & $2(5.7 \%)$ & $1(5.6 \%)$ & $3(5.7 \%)$ & $0.979^{\text {ns }}$ \\
\hline 40-49 years & $4(11.4 \%)$ & $2(11.1 \%)$ & $6(11.3 \%)$ & \\
\hline $50-59$ years & $10(28.6 \%)$ & $5(27.8 \%)$ & $15(28.3 \%)$ & \\
\hline $60-69$ years & $15(48.9 \%)$ & $7(38.9 \%)$ & $22(41.5 \%)$ & \\
\hline e"70 years & $4(11.4 \%)$ & $3(16.7 \%)$ & $7(13.2 \%)$ & \\
\hline Total & $35(100.0 \%)$ & $18(100.0 \%)$ & $53(100.0 \%)$ & \\
\hline Mean $\pm S D$ & $58.4 \pm 9.28$ & $59.71 \pm 10.89$ & $58.83 \pm 9.85$ & \\
\hline Range(Min - Max) years & \multicolumn{2}{|c|}{$35-77$} & & \\
\hline
\end{tabular}

ns: significant $(P$ value $>0.05)$, figures in the parentheses indicate correspondingpercentage; Chi-squared $\left(c^{2}\right)$ Test was done to analyze the data.

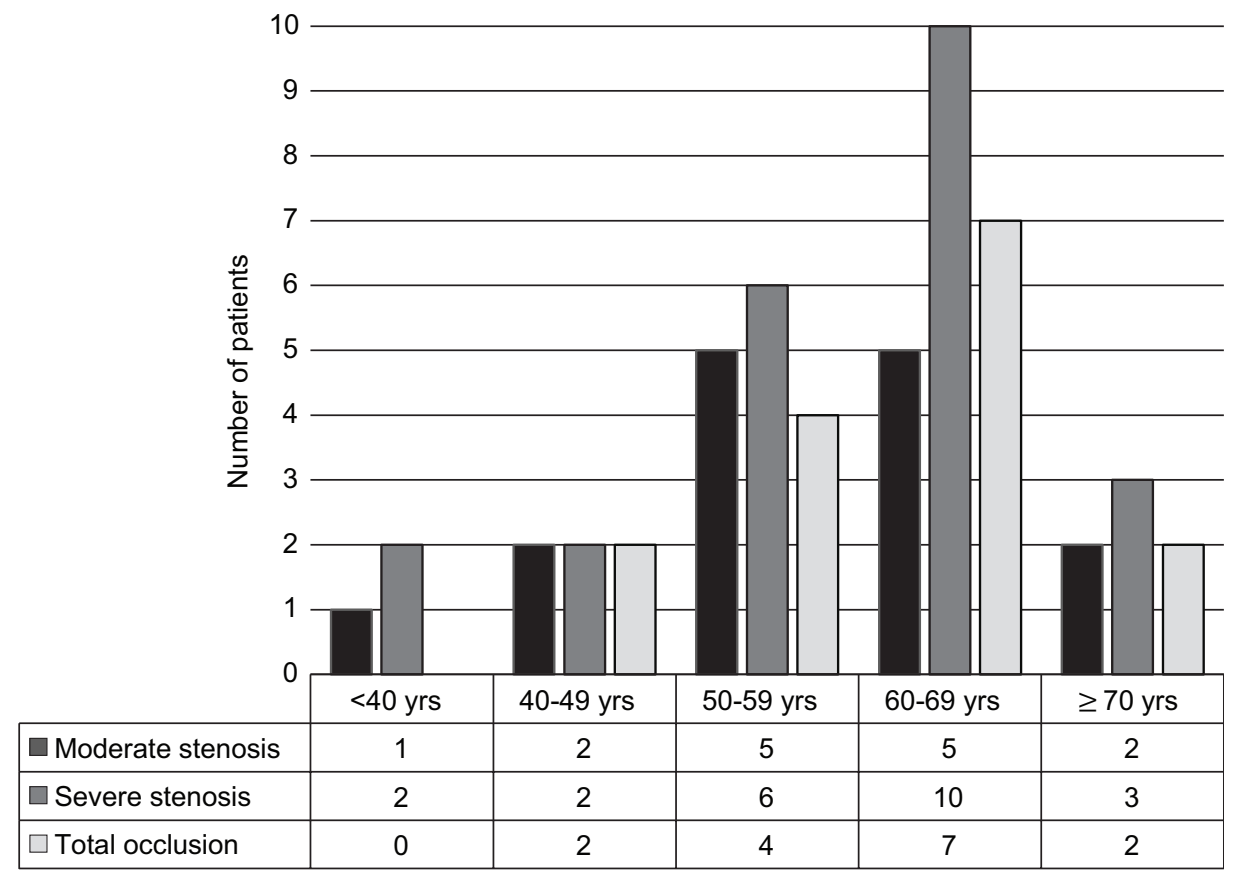

Fig.-2: Bar diagram showing distribution of age of the study population according to severity of stenosis $(n=53)$. 


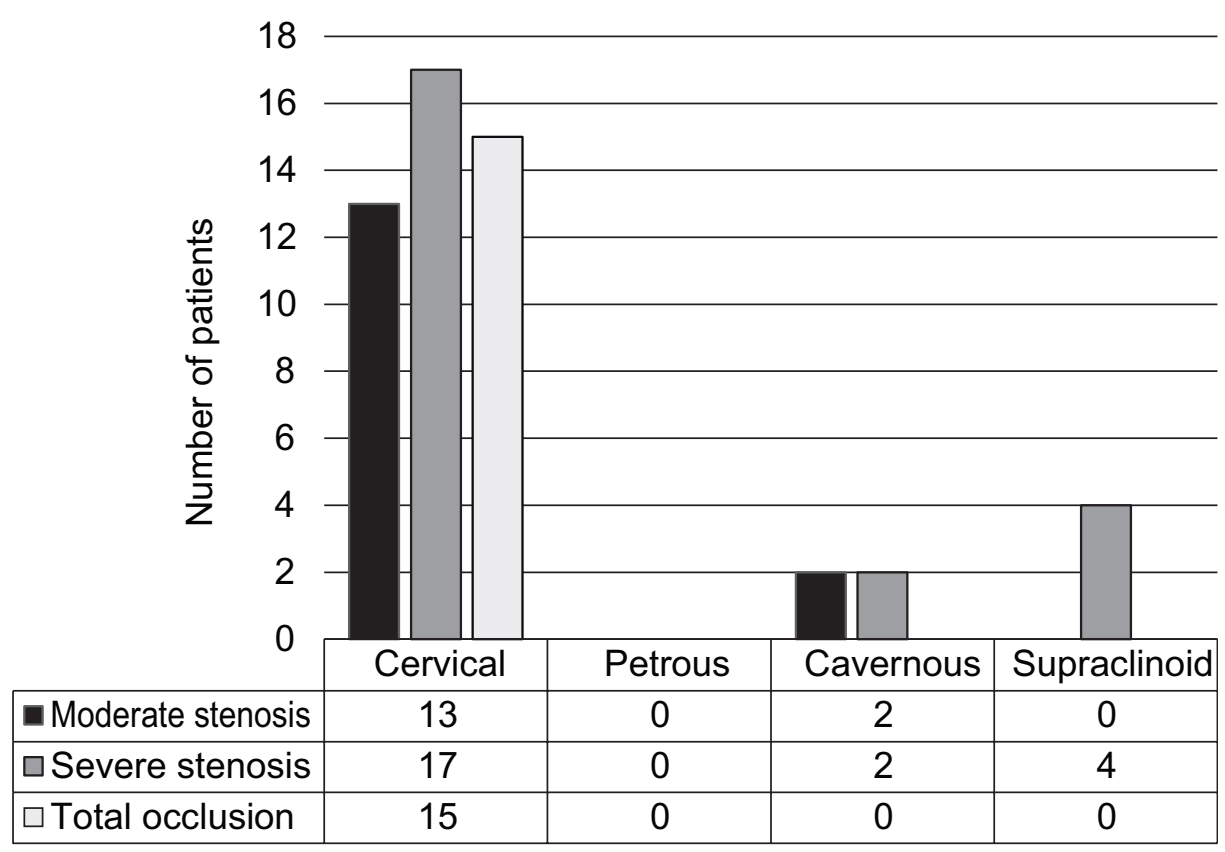

Fig.-3: Bar diagram showing distribution of different segments of ICA according to severity of stenosis $(n=53)$.

Table-II

Distribution of different segments of ICA according to subtype of infarct ( $n=53)$

\begin{tabular}{|c|c|c|c|c|c|c|}
\hline \multirow[t]{2}{*}{ Segment of ICA } & \multicolumn{4}{|c|}{ Subtype of Infarct } & \multirow{2}{*}{$\begin{array}{l}\text { Total } \\
(n=53) \\
\text { No. }(\%)\end{array}$} & \multirow[t]{2}{*}{$p$-value } \\
\hline & $\begin{array}{c}\text { Territorial } \\
(n=25) \\
\text { No. }(\%)\end{array}$ & $\begin{array}{c}\text { Subcortical } \\
\qquad(n=9) \\
\text { No. }(\%)\end{array}$ & $\begin{array}{l}\text { Lacunar } \\
(n=13) \\
\text { No. }(\%)\end{array}$ & $\begin{array}{c}\text { Watershed } \\
(n=6) \\
\text { No. }(\%)\end{array}$ & & \\
\hline Cervical & $24(53.3 \%)$ & $7(15.6 \%)$ & $8(17.8 \%)$ & $6(13.3 \%)$ & $45(100 \%)$ & $0.041^{*}$ \\
\hline Cavernous & $0(0.0 \%)$ & $2(50.0 \%)$ & $2(50.0 \%)$ & $0(0.0 \%)$ & $4(100 \%)$ & \\
\hline Supraclinoid & $1(25.0 \%)$ & $0(0.0 \%)$ & $3(75.0 \%)$ & $0(0.0 \%)$ & $4(100 \%)$ & \\
\hline$\overline{\text { Total }}$ & $25(47.2 \%)$ & $9(17.0 \%)$ & $13(24.5 \%)$ & $6(11.3 \%)$ & $53(100 \%)$ & \\
\hline
\end{tabular}

* significant (P value d" 0.05), figures in the parentheses indicate correspondingpercentage; Chi-squared $\left(\mathrm{c}^{2}\right)$ Test was done to analyze the data.

Table-III

Distribution of severity of stenosis according to subtype of infarct $(n=53)$

\begin{tabular}{|c|c|c|c|c|c|c|}
\hline \multirow{2}{*}{$\begin{array}{l}\text { Severity of } \\
\text { Stenosis }\end{array}$} & \multicolumn{4}{|c|}{ Subtype of Infarct } & \multirow{2}{*}{$\begin{array}{c}\text { Total } \\
(n=53) \\
\text { No. }(\%)\end{array}$} & \multirow[t]{2}{*}{$p$-value } \\
\hline & $\begin{array}{c}\text { Territorial } \\
(\mathrm{n}=25) \\
\text { No. }(\%)\end{array}$ & $\begin{array}{c}\text { Subcortical } \\
(n=9) \\
\text { No. }(\%)\end{array}$ & $\begin{array}{c}\text { Lacunar } \\
(\mathrm{n}=12) \\
\text { No. }(\%)\end{array}$ & $\begin{array}{c}\text { Watershed } \\
(n=6) \\
\text { No. }(\%)\end{array}$ & & \\
\hline Moderate & $5(33.3 \%)$ & $6(40.0 \%)$ & $4(26.7 \%)$ & $0(0.0 \%)$ & $15(100 \%)$ & $0.003^{*}$ \\
\hline Severe & $9(39.1 \%)$ & $4(17.4 \%)$ & $8(34.8 \%)$ & $2(8.7 \%)$ & $23(100 \%)$ & \\
\hline Total occlusion & $11(73.3 \%)$ & $0(0.0 \%)$ & $0(0.0 \%)$ & $4(26.7 \%)$ & $15(100 \%)$ & \\
\hline Total & $25(47.2 \%)$ & $10(18.9 \%)$ & $12(22.6 \%)$ & $6(11.3 \%)$ & $53(100 \%)$ & \\
\hline
\end{tabular}

* significant $(P$ value $\leq 0.05)$, figures in the parentheses indicate correspondingpercentage;

Chi-squared $\left(\chi^{2}\right)$ Test was done to analyze the data. 
Table-IV

Distribution of territory of infarction according severity of stenosis $(n=25)$

\begin{tabular}{|c|c|c|c|c|c|}
\hline \multirow{2}{*}{$\begin{array}{l}\text { Territory of } \\
\text { Infarct }\end{array}$} & \multicolumn{3}{|c|}{ Severity of Stenosis } & \multirow{2}{*}{$\begin{array}{c}\text { Total } \\
(n=25) \\
\text { No. }(\%)\end{array}$} & \multirow[t]{2}{*}{$p$-value } \\
\hline & $\begin{array}{c}\text { Moderate } \\
\text { stenosis } \\
(n=5) \\
\text { No. }(\%) \\
\end{array}$ & $\begin{array}{c}\text { Severe } \\
\text { stenosis } \\
(n=9) \\
\text { No. }(\%)\end{array}$ & $\begin{array}{c}\text { Total } \\
\text { occlusion } \\
(n=11) \\
\text { No. }(\%) \\
\end{array}$ & & \\
\hline$\overline{\mathrm{ACA}}$ & $1(20.0 \%)$ & $0(0.0 \%)$ & $0(0.0 \%)$ & $1(4.0 \%)$ & $0.247^{\mathrm{ns}}$ \\
\hline MCA & $4(80.0 \%)$ & $9(100.0 \%)$ & $10(90.9 \%)$ & $23(92.0 \%)$ & \\
\hline PCA & $0(0.0 \%)$ & $0(0.0 \%)$ & $1(9.1 \%)$ & $1(4.0 \%)$ & \\
\hline Total & $5(100.0 \%)$ & $9(100.0 \%)$ & $11(100.0 \%)$ & $25(100.0 \%)$ & \\
\hline
\end{tabular}

ns: significant $(P$ value $>0.05)$, figures in the parentheses indicate correspondingpercentage;

Chi-squared $\left(\mathrm{c}^{2}\right)$ Test was done to analyze the data.

\section{Discussion:}

Total 53 ischemic stroke patients with significant symptomatic stenosis of ICA were studied. Analysis of age distribution showed that mean age was $58.83 \pm 9.85$ years with range from $35-77$ years. 60 69 year group was seen most commonly encountered $(41.5 \%)$. There was no significant association found between age of the study population and location of stenosis. An epidemiological survey of stroke in Bangladesh ${ }^{15}$ revealed that highest prevalence of stoke was among 65-79 years of age. Another DSA based study $^{16}$ from BSMMU revealed mean age was $61.55 \pm 8.85$ years with 60-69 year group being most commonly $(42.9 \%)$ encountered. Another DSA based study ${ }^{17}$ among diabetic patients revealed mean age was $57.9 \pm 9.2$ years. A study ${ }^{18}$ in India found mean age $57.97 \pm 10.75$ years with most commonly affected patients were above 60 years of age and no association between stenosis and age. These results are almost similar to our study.

In our study, among 53 patients, 35 were male and 18 were female with male female ratio 1.51:1. There was no association found between sex of patient and location of stenosis. A study ${ }^{15}$ revealed that male female ratio was 1.94:1. In another DSA based study ${ }^{19}$ found male female ratio was 1.65:1. The reason behind this discrepancy in male female ratio may be explained by increased incidence of stroke in male and also negligence of female ischemic stroke patients.
Our study with 53 patients revealed, 15(28.3\%) patients had moderate stenosis, $23(43.4 \%)$ patients had severe stenosis and $15(28.3 \%)$ patients had total occlusion of ICA. In a recent study at $\mathrm{BSMMU}^{16}$, moderate, severe and total occlusion were observed in $26.2 \%, 40.5 \%$ and $33.3 \%$ respectively among 42 patients.

In our study among 53 ICA stenotic segments, $84.9 \%$ were in cervical segment, $7.5 \%$ were in cavernous segment and $7.5 \%$ were in supraclinoid segment. No patient had stenosis in petrous part. The total occlusion of ICA was always observed in cervical segment. Among 45 patients with stenosis of cervical segment of ICA, $53.3 \%$ had territorial infarct, $17.8 \%$ had lacunar infarct, $15.6 \%$ had subcortical infarct and $13.3 \%$ had watershed infarct. Among 4 patients with stenosis in cavernous part $50.0 \%$ had subcortical and $50.0 \%$ lacunar infarct. And among 4 patients with supraclinoid stenosis $75.0 \%$ had lacunar and $25.0 \%$ had territorial infarct. This observation was statistically significant.

A study ${ }^{20}$ of large vessel atherosclerotic cerebrovascular disease revealed among 277 patients with ICA disease, $91.7 \%$ had cervical segment involvement and $8.3 \%$ had intracranial involvement. Total occlusion was observed in 82 patients among them $95.1 \%$ had occlusion in cervical segment. Another study ${ }^{21}$ about infarct volume and pattern of ICA disease revealed that, among 47 patients $48.9 \%$ presented with watershed zone infarct, $14.9 \%$ with subcortical 
infarct, $14.9 \%$ with lacunar infarct and $10.6 \%$ with large territorial infarct. A study ${ }^{22}$ comparing infarct pattern between MCA and ICA disease revealed that, among 63 patients with ICA disease $27 \%$ had lacunar infarct and $73 \%$ had territorial infarct. Another study ${ }^{23}$ of 31 patients with severe to total occlusion of ICA revealed $67.7 \%$ had territorial infarction and $32.3 \%$ had watershed zone infarct. These studies revealed almost same findings as ours.

We found significant difference between subtype of infarct and severity of stenosis ( $p$-value = 0.003).Among 15 patients with moderate stenosis of ICA, $66.7 \%$ presented with subcortical or lacunar infarction and $33.0 \%$ presented with territorial infarction. In case of severe stenosis, territorial, lacunar and watershed infarct were 9(39.1\%), $8(34.8 \%)$ and $2(8.7 \%)$ respectively. Whereas total occlusion of ICA presented as either territorial infarction (73.3\%) or watershed infarction (26.7\%). An MRI based study ${ }^{8}$ about acute ischemic stroke pattern revealed, among 19 patients with moderate stenosis $36.8 \%$ had lacunar infarct and $26.3 \%$ had subcortical infarct. Among 41 patients with severe stenosis, $51.2 \%$ had watershed infarct and $26.8 \%$ had territorial infarct and among 42 patients with total occlusion, $61.9 \%$ had territorial infarct and $21.4 \%$ had watershed zone infarct. Another study ${ }^{23}$ of 31 patients with ICA stenosis of $70 \%$ or more revealed $67.7 \%$ had territorial infarction and $32.3 \%$ had watershed zone infarct. In another large study ${ }^{24}$ among 413 ischemic stroke patients with ICA disease, $33.4 \%$ had lacunar infarct and $26.2 \%$ had watershed zone infarct. They also showed that $63 \%$ of watershed infarct was encountered in ICA stenosis of $70 \%$ or more, whereas $42 \%$ of such patients presented with lacunar infarct.

Among 53 patients with ICA stenosis, we found 25 patients with territorial infarction. $92.0 \%$ had infarction in MCA territory, $4.0 \%$ had infarction in PCA territory and $4.0 \%$ had infarction in ACA territory. A large study ${ }^{25}$ revealed that MCA was the most frequently involved territory $(49.6 \%)$ and PCA was involved in (8.5\%). Another hospitalbased study of young patient with ischemic stroke ${ }^{26}$ revealed $21.86 \%$ had large artery stenosis among them $77.7 \%$ had MCA territory infarct. ADSA based study ${ }^{27}$ from India revealed, among 161 patients, $81.5 \%$ had MCA territory infarction, $4.35 \%$ had PCA and $1.2 \%$ had ACA territory infarction. Another study ${ }^{28}$ about the etiology of MCA territory infarct showed that, $40 \%$ ICA occlusion was found among MCA territory infarct.

\section{Conclusion:}

The present study revealed that, ischemic stroke patients had more cervical segment of ICA involvement than intracranial part of ICA. Territorial infarction was more commonly associated with severe stenosis and lacunar stroke was more commonly associated with moderate stenosis. Watershed infarction was an indicator of severe stenosis.

\section{Ethical issues:}

All patients gave informed written consents and the study was approved by Institutional Review Board of Bangabandhu Sheikh Mujib Medical University.

\section{Conflict of interests:}

The authors declare that they have no conflict of interest.

\section{Abbreviations}

ACA: Anterior Cerebral Artery, BSMMU: Bangabandhu Sheikh Mujib Medical University, CTA: Computed Tomography Angiogram, DSA: Digital Subtraction Angiography, ICA: Internal Carotid Artery, MCA: Middle Cerebral Artery, MRA: Magnetic Resonance Imaging, NASCET: North American Symptomatic Carotid Endarterectomy Trial, PCA: Posterior Cerebral Artery, SD: Standard Deviation, TOF: Time of Flight MRI.

\section{References:}

1. Lindsay MP, Norrving B, Sacco RL, Brainin M, Hacke W, Martins S, Pandian J, Feigin V. World Stroke Organization (WSO): global stroke fact sheet 2019.

2. Johnson W, Onuma O, Owolabi M, Sachdev S. Stroke: a global response is needed. Bulletin of the World Health Organization. 2016 Sep 1;94(9):634.

3. World Health Rankings. World Life Expectency: 2020 [updated 2020 Sep 21; 
cited 2020 Sep 21].Available from: https:// www.worldlifeexpectency.com/bangladeshstroke

4. Dey SK, Shahidullah M, Ahmed A, Habib A, Rizvi AN. Prognosis of ischemic stroke patients with or without collateralization after carotid stenosis. Bangabandhu Sheikh Mujib Medical University Journal. 2018 Dec 25;11(4):270-3.

5. Rothwell PM. Carotid artery disease and the risk of ischaemic stroke and coronary vascular events. Cerebrovascular Diseases. 2000;10(Suppl. 5):21-33.

6. Banerjee C, Chimowitz MI. Stroke caused by atherosclerosis of the major intracranial arteries. Circulation research. 2017 Feb 3;120(3):502-13.

7. Lee PH, Oh SH, Bang OY, Joo SY, Joo IS, Huh K. Infarct patterns in atherosclerotic middle cerebral artery versus internal carotid artery disease. Neurology. 2004 Apr 27;62(8):1291-6.

8. Szabo K, Kern R, Gass A, Hirsch J, Hennerici M. Acute stroke patterns in patients with internal carotid artery disease: a diffusionweighted magnetic resonance imaging study. Stroke. 2001 Jun;32(6):1323-9.

9. Donnan GA, Davis SM, Chambers BR, Gates PC. Surgery for prevention of stroke. Lancet (London, England). 1998 May 1;351(9113):1372-3.

10. Pu Y, Liu L, Wang Y, Zou X, Pan Y, Soo Y, Leung $\mathrm{T}$, Zhao $\mathrm{X}$, Wong $\mathrm{KS}$, Wang $\mathrm{Y}$. Geographic and sex difference in the distribution of intracranial atherosclerosis in China. Stroke. 2013 Aug;44(8):2109-14.

11. Kim JS, Nah HW, Park SM, Kim SK, Cho KH, Lee J, Lee YS, Kim J, Ha SW, Kim EG, Kim $\mathrm{DE}$. Risk factors and stroke mechanisms in atherosclerotic stroke: intracranial compared with extracranial and anterior compared with posterior circulation disease. Stroke. 2012 Dec;43(12):3313-8.

12. Tatu L, Moulin T, Bogousslavsky J, Duvernoy $\mathrm{H}$. Arterial territories of the human brain: cerebral hemispheres. Neurology. 1998 Jun 1;50(6):1699-708.

13. Nakano $\mathrm{S}$, Yokogami $\mathrm{K}$, Ohta $\mathrm{H}$, Goya $\mathrm{T}$, Wakisaka S. CT-defined large subcortical infarcts: correlation of location with site of cerebrovascular occlusive disease. American journal of neuroradiology. 1995 Sep 1;16(8):1581-5.

14. Cloud G, Markus H, Pereira A. Oxford Specialist Handbooks in Neurology Stroke Medicine.

15. Saha UK, Alam MB, Rahman AK, Hussain AH, Mashreky SR, Mandal G, Mohammad QD. Epidemiology of stroke: findings from a community-based survey in rural Bangladesh. Public health. 2018 Jul 1;160:26-32.

16. Hossain MA, Rahman $H Z$, Shahidullah $M$, Islam MR, Hannan MA, Rizvi AZ, ... Islam MM. Digital subtraction angiographic pattern of extracranial and intracranial atherosclerotic arterial stenosis among ischemic stroke patients. Bangladesh Journal of NeuroScience. 2017;33(2):89-95.

17. Chowdhury MS, Islam M, Chowdhury AH, Ahmed S, Baqui M, Rahman M, Khan SU, Mohammad QD. Digital subtraction angiography evaluation of extracranial and intracranial atherosclerotic arterial stenosis in patients of ischemic stroke with diabetes mellitus. Bangladesh Medical Journal. 2013;42(1):28-30.

18. Shrivastava A, Srivastava T, Saxena R. CT angiographic evaluation of pattern and distribution of stenosis and its association with risk factors among Indian ischemic stroke patients. Polish journal of radiology. 2016;81:357.

19. Borhani-Haghighi A, Emami M, Vasaksi AS, Shariat A, Banihashemi MA, Nikseresht A, Ashjazadeh N, Izadi S, Petramfar P, Poursadegh $M$, Jaberi AR. Large-vessel stenosis in the patients with ischemic stroke in Iran: Prevalence, pattern, and risk factors. journal of vascular and interventional neurology. 2015 Feb;8(1):11. 
20. Flaherty ML, Kissela B, Khoury JC, Alwell K, Moomaw CJ, Woo D, Khatri P, Ferioli S, Adeoye O, Broderick JP, Kleindorfer D. Carotid artery stenosis as a cause of stroke. Neuroepidemiology. 2013;40(1):36-41.

21. Jung JM, Kwon SU, Lee JH, Kang DW. Difference in infarct volume and patterns between cardioembolism and internal carotid artery disease: focus on the degree of cardioembolic risk and carotid stenosis. Cerebrovascular Diseases. 2010;29(5):4906.

22. Lee DK, Kim JS, Kwon SU, Yoo SH, Kang DW. Lesion patterns and stroke mechanism in atherosclerotic middle cerebral artery disease: early diffusion-weighted imaging study. Stroke. 2005 Dec 1;36(12):2583-8.

23. Kang DW, Chu K, Ko SB, Kwon SJ, Yoon BW, Roh JK. Lesion patterns and mechanism of ischemia in internal carotid artery disease: a diffusion-weighted imaging study. Archives of neurology. 2002 Oct 1;59(10):1577-82.

24. Del Sette M, Eliasziw M, Streifler JY, Hachinski VC, Fox AJ, Barnett HJ. Internal borderzone infarction: a marker for severe stenosis in patients with symptomatic internal carotid artery disease. Stroke. 2000 Mar;31(3):631-6.

25. Chung JW, Park SH, Kim N, Kim WJ, Park JH, Ko Y, Yang MH, Jang MS, Han MK, Jung C, Kim JH. Trial of ORG 10172 in Acute Stroke Treatment (TOAST) classification and vascular territory of ischemic stroke lesions diagnosed by diffusion weighted imaging. Journal of the American Heart Association. 2014 Aug 11;3(4):e001119.

26. Habib R, Hosen I, Islam R, Bhowmik NB. Risk Factors and Etiologies of Ischemic Stroke in Young Adults: A Hospital-based Study in Bangladesh. BIRDEM Medical Journal. 2018 May 16;8(2):138-44.

27. Totlani SI, Tyagi A. A Study of the Angiographic Profile and Risk Factors in Patients of Ischemic Stroke. International Journal of Medical Science and Clinical Inventions. 2017;4(1):2529-2532.

28. Heinsius T, Bogousslavsky J, Van Melle G. Large infarcts in the middle cerebral artery territory Etiology and outcome patterns. Neurology. 1998 Feb 1;50(2):341-50. 